\title{
Dipole Moment Studies of Some Substituted of Anilines with 2-methoxy ethanol
}

\author{
R. Priscilla ${ }^{1}$, S. Balamuralikrishnan ${ }^{2}$ \\ ${ }^{1}$ Department of Physics, A.D.M.College for Women (Autonomous), Nagapattinam-611001, TamilNadu, India \\ ${ }^{2}$ Department of Physics, Annamalai University, Chidambaram,TamilNadu,India
}

\begin{abstract}
The dipolemoment have been determined by using the mixtures of aniline, o-chloro aniline, p-chloro aniline and 2methoxy ethanol at $30^{\circ} \mathrm{C}$ based on the Onsager theory and Huysken's method. The dipolar increments of the systems were computed from the bond angle data available from molecular orbital theory. The enhancement of the dipole moment values confirms the hydrogen bonding between all the systems.
\end{abstract}

Keywords: H-Bonding, 2-methoxy ethanol, Aniline, o-chloroaniline, p-chloroaniline, Dipole moment, Dipolar increment

\section{Introduction}

Dielectric studies provide meaningful information about the mechanisms, which describe the intra-intermolecular orientations of these molecules.Amoung the physicochemical methos used in the investigation of the nature of molecular complexes there are the phenomena of molecular orientation by a particular permanent electric field.Hoffman and Symth ${ }^{1}$ have calculated the dielectric constant of ndocosyl bromide in the solid rotator phase applying Onsager's equation and modifying extensively the theory of Fowler $^{2}$ that assured a fraction of the molecules to be rotating. The dipole moment $\mu \mathrm{AB}$ of the complex formed between the proton donor group A-H and acceptor group B. Dielectric measurements on acctophenone and its derivatives have been made by various workers ${ }^{3-6}$. The formation of hydrogen bond leads to an increased the polarity of the A-H (Proton donor) and hence to large dielectric constant and dipole moment. Huyskens et al. ${ }^{7,8}$ has developed the methods to determine the stereo chemistries of hydrogen bonded complexes from the proton acceptor in an inert solvent. The dipole moment of the complex is a function of the relative strength of acid and base can be calculated. Alcohols are excellent proton donors. In hydrogen bonded complexes, a redistribution of electron density can occur due to three types of interactions namely, electrostatic, polarization and charge - transfer interaction. The interaction due to electro static effects does not contribute significantly to the dipole moment of the complex, but the polarization effect results in a significant change in the dipole moment value due to appreciable charge distribution. In the event of charge transfer interaction, charge migration parallel to the H-bonded axis will yield a large change in the dipole moment. Thus, the experimental determination of dipole moment of the complexes serves as an indication of the nature of the interaction involved in the formation of the complexes.The most important characteristics of the hydrogen bond are the increase in the distance of $\mathrm{OH}$ accompanied by an enhancement of the bond moment $\Delta \mu$. The dipole moment of the complexes higher than the sum of the individual components corresponds to charge redistribution along the A-H.....B Bond. In this paper, reporting the dipole moment of the 1:1 complexes of aniline, o-chloro aniline and p-chloro aniline with 2-methoxy ethanol. We have undertaken the investigation of complex formation involving aniline - ethanol in non-polar solvent based on Onsager's method ${ }^{9}$.

\section{Experimental}

The dielectric measurements were measured at static frequency $300 \mathrm{KHZ}$ by Toshniwal RL09 type dipole meter. The dipole meter was calibrated using standard liquids. The cell temperature was maintained at $303 \mathrm{~K}$ by circulating water through the glass jacket of the cell. The refractive indices were measured at the same temperature using Abbe's refractometer. Densities were determined using $10 \mathrm{ml}$ specific gravity bottle and a SHIMADZU - ATY224 digital balance. Chemicals are purified by standard procedure. The Physical parameters of all the chemicals were checked against their literature values.

\section{Theory}

Huyskens et al. ${ }^{7,8}$ developed methods to obtain the overall dipole moment of a system of solute- solvent mixtures. The method well suited for ternary mixtures of two polar components A (donor) and B (acceptor) in an apolar solvent in liquid phase, where a great mobility is envisaged. Using the Onsager theory ${ }^{9}$, the overall dipole moment $[\mathrm{M}]$ of a solution containing polar substances and a polar solvent is given by:

Considering the ternary mixture of polar components A ($\mathrm{OH}$ group) and $\mathrm{B}\left(-\mathrm{NH}_{2}\right.$ group) in a non- polar solvent, the relative orientations of $\mathrm{A}$ and $\mathrm{B}$ vary continuously due to the mobility of the liquid phase. Assuming that the time interval is short enough to consider the orientation as fixed, the dipole moment of the solution may be written as $\mathbf{M}^{2}$

$$
=\sum_{\mathrm{i}=0}^{\infty} \sum_{\mathrm{j}=0}^{\infty} \mathrm{N}_{\mathrm{ij}} \mu_{\mathrm{ij}}
$$

where $\mathrm{N}$ is the number of ij ensembles. Huyskens et al., showed that equation. 1 can be written as

$$
M^{2}=\sum_{i=0}^{\infty} \sum_{j=0}^{\infty} N_{i j}\left[\frac{\mu_{i j}^{2}-j<\mu_{o j} / j>}{i}\right]+n_{B}<\mu_{o j}^{2} / j>N_{B}(2)
$$

Where $\left\langle\mu_{\mathrm{oj}} / \mathrm{j}\right\rangle$ is the mean square of the B molecule in the square of the total dipole moment of the entities. For anilines

\section{Volume 6 Issue 1, January 2017




\section{International Journal of Science and Research (IJSR) \\ ISSN (Online): 2319-7064 \\ Index Copernicus Value (2015): 78.96 | Impact Factor (2015): 6.391}

as proton donor $\mathrm{B}, \mathrm{j}$ is taken as 1 and $\left\langle\mu_{\mathrm{oj}} / \mathrm{j}\right\rangle$ is practically $\mu_{\mathrm{b}}^{2}$.

The quantity $\frac{\mu_{i j}^{2}-\mu_{\mathrm{oj}} / \mathrm{j}>}{\mathrm{i}}$ represents the mean share of the A molecule nthe square of the total dipole moment of the entities.

$$
\begin{gathered}
\mathrm{n}_{\mathrm{A}}=\sum_{\mathrm{i}=0}^{\infty} \mathrm{iN}_{\mathrm{ij}} / \mathrm{N}_{\mathrm{A}} \\
\mathrm{n}_{\mathrm{B}}=\sum_{\mathrm{i}=0}^{\infty} \mathrm{iN}_{\mathrm{ij}} / \mathrm{N}_{\mathrm{B}} \\
\frac{\mathrm{M}^{2}}{\mathrm{VN}_{\mathrm{A}}}=\left(<\mu_{\mathrm{ab}}^{2}-\mu_{\mathrm{b}}^{2}>\mathrm{C}_{\mathrm{a}}+<\mu_{\mathrm{b}}^{2}>\mathrm{C}_{\mathrm{b}}\right)
\end{gathered}
$$

Where $C_{a}$ and $C_{b}$ are the formal concentration $\left(\mathrm{mol} \mathrm{dm}^{-3}\right)$ of the proton donor and proton acceptor, respectively.

From the knowledge of dielectric constant $\varepsilon_{0}$, the refractive index $\mathrm{n}_{\mathrm{d}}$ of the solution $\varepsilon_{\mathrm{S}}$ and $\mathrm{n}_{\mathrm{DS}}$ of the solvent. One can obtain a relation for $\mathrm{M}^{2}$ from Frohlich equation.9.

The experimental values of the density, refractive index, dielectric constant and experimental quantity $\left(\Omega_{\mathrm{B}}\right)$ for
$\left.\mathrm{M}^{2}=\frac{9 \mathrm{KT}}{4 \pi}\left[\frac{\left(\epsilon_{0}-\mathrm{n}_{\mathrm{D}}^{2}\right)\left(2 \epsilon_{0}+\mathrm{n}_{\mathrm{D}}^{2}\right)}{\varepsilon_{0\left(\mathrm{n}_{\mathrm{D}}^{2}+2\right)^{2}}^{2}}\right]-\frac{\mathrm{F}_{\mathrm{S}}}{\overline{\mathrm{F}}_{\mathrm{S}}}\left[\frac{\left(\epsilon_{\mathrm{S}}-\mathrm{n}_{\mathrm{DS}}^{2}\right)\left(2 \epsilon_{\mathrm{S}}+\mathrm{n}_{\mathrm{DS}}^{2}\right)}{\varepsilon_{\mathrm{S}\left(\mathrm{n}_{\mathrm{DS}}^{2}+2\right)^{2}}^{2}}\right] 6\right)$ is the actual concentration of the polar solvent and $\overline{\mathrm{F}}_{\mathrm{S}}$ is the concentration in its pure state. Substitute equation $\left(<\mu_{\mathrm{ab}}^{2}-\mu_{\mathrm{b}}^{2}>\right) \frac{\mathrm{c}_{\mathrm{a}}}{\mathrm{c}_{\mathrm{b}}}+\mu_{\mathrm{b}}^{2} \Omega_{\mathrm{B}}=\left[\frac{\left(\epsilon_{0}-\mathrm{n}_{\mathrm{D}}^{2}\right)\left(2 \epsilon_{0}+\mathrm{n}_{\mathrm{D}}^{2}\right)}{\varepsilon_{0\left(\mathrm{n}_{\mathrm{D}}^{2}+2\right)^{2}}}\right]-$ $\frac{\mathrm{F}_{\mathrm{S}}}{\overline{\mathrm{F}}_{\mathrm{S}}}\left[\frac{\left(\epsilon_{\mathrm{S}}-\mathrm{n}_{\mathrm{DS}}^{2}\right)\left(2 \epsilon_{\mathrm{S}}+\mathrm{n}_{\mathrm{DS}}^{2}\right)}{\varepsilon_{\mathrm{S}\left(\mathrm{n}_{\mathrm{DS}}^{2}+2\right)^{2}}}\right](7)$

If $\mu_{\mathrm{a}}, \mu_{\mathrm{b}}$ and $\mu_{\mathrm{ab}}$ are the dipole moments of proton donor, proton acceptor and their 1:1 complexes respectively and at concentrations when self- association of the polar components are negligible, Huyskens et al., ${ }^{7}$ showed that: $\mathrm{M}^{2}=\mathrm{V} \mathrm{N} \mathrm{N}_{\mathrm{A}}\left(\bar{\mu}_{\mathrm{ab}}^{2}-\bar{\mu}_{\mathrm{b}}^{2}\right) \mathrm{C}_{\mathrm{A}}+\bar{\mu}_{\mathrm{b}}^{2} \mathrm{C}_{\mathrm{B}}(8)$

different concentrations for the system studies here are given in Table 1 and Table 3.

Table 1: Values of Dielectric Constant, Refractive Index and Density of anliline, o-chloro aniline and p-chloro aniline with the formal concentration of 2- methoxy ethanol 2-methoxyethanol +aniline in $\mathrm{ccl}_{4}$ System

\begin{tabular}{|c|c|c|c|c|c|}
\hline $\begin{array}{c}\text { Mole Fraction of the } \\
\text { Solute } \mathrm{X}_{2}\end{array}$ & $\begin{array}{c}\text { Dielectric Constant of the } \\
\text { Solution } \varepsilon_{12}\end{array}$ & $\begin{array}{c}\text { Refractive Index of } \\
\text { the Solution } \mathrm{n}_{12}\end{array}$ & $\begin{array}{c}\text { Density of the } \\
\text { Solution } \mathrm{d}_{12}\end{array}$ & $\Omega_{\mathrm{B}}$ & $\mu_{\mathrm{b}}{ }^{2}$ \\
\hline 0.05 & 2.0453 & 1.489 & 1.6390 & 17.4628 & 17.477 \\
\hline 0.1 & 2.1041 & 1.4791 & 1.6379 & 5.0332 & 5.048 \\
\hline 0.2 & 2.1103 & 1.4770 & 1.6377 & 1.6405 & 1.655 \\
\hline 0.3 & 2.223 & 1.4750 & 1.6372 & 0.5724 & 0.5874 \\
\hline 0.4 & 2.2404 & 1.4730 & 1.6368 & 0.5192 & 0.5337 \\
\hline 0.5 & 2.260 & 1.4710 & 1.6319 & 0.5195 & 0.5195 \\
\hline
\end{tabular}

2-methoxyethanol + o-chloroaniline in ccl $_{4}$ System

\begin{tabular}{|c|c|c|c|c|c|}
\hline $\begin{array}{c}\text { Mole Fraction of the } \\
\begin{array}{c}\text { Solute } \\
\mathrm{X}_{2}\end{array}\end{array}$ & $\begin{array}{c}\text { Dielectric Constant of the } \\
\text { Solution } \\
\varepsilon_{12}\end{array}$ & $\begin{array}{c}\text { Refractive Index of } \\
\text { the Solution } \\
\mathrm{n}_{12}\end{array}$ & $\begin{array}{c}\text { Density of the } \\
\text { Solution } \\
\mathrm{d}_{12}\end{array}$ & $\Omega_{\mathrm{B}}$ & $\mu_{\mathrm{b}}{ }^{2}$ \\
\hline 0.05 & 2.0472 & 1.4044 & 1.6408 & 11.518 & 11.518 \\
\hline 0.1 & 2.1816 & 1.4042 & 1.6350 & 11.133 & 11.1452 \\
\hline 0.2 & 2.2209 & 1.3940 & 1.6339 & 6.8657 & 6.8778 \\
\hline 0.3 & 2.2397 & 1.3938 & 1.6329 & 3.9643 & 3.9764 \\
\hline 0.4 & 2.3582 & 1.3936 & 1.6323 & 3.4717 & 3.4839 \\
\hline 0.5 & 2.3780 & 1.3932 & 1.6303 & 2.4969 & 2.5096 \\
\hline
\end{tabular}

2-methoxyethanol + p-chloroaniline in $\operatorname{ccl}_{\mathbf{4}}$ System

\begin{tabular}{|c|c|c|c|c|c|}
\hline $\begin{array}{c}\text { Mole Fraction of the } \\
\begin{array}{c}\text { Solute } \\
\mathrm{X}_{2}\end{array}\end{array}$ & $\begin{array}{c}\text { Dielectric Constant of the } \\
\text { Solution } \\
\varepsilon_{12}\end{array}$ & $\begin{array}{c}\text { Refractive Index of } \\
\text { the Solution } \\
\mathrm{n}_{12}\end{array}$ & $\begin{array}{c}\text { Density of the } \\
\text { Solution } \\
\mathrm{d}_{12}\end{array}$ & $\Omega_{\mathrm{B}}$ & $\mu_{\mathrm{b}}{ }^{2}$ \\
\hline 0.05 & 2.1163 & 1.4041 & 1.6408 & 22.0359 & 22.0496 \\
\hline 0.1 & 2.2317 & 1.3938 & 1.6350 & 18.572 & 18.5858 \\
\hline 0.2 & 2.2602 & 1.3936 & 1.6329 & 7.8267 & 7.8403 \\
\hline 0.3 & 2.3170 & 1.3932 & 1.6323 & 4.97234 & 4.9859 \\
\hline 0.4 & 2.3877 & 1.3828 & 1.6329 & 3.9758 & 3.9894 \\
\hline 0.5 & 2.4165 & 1.3823 & 1.6249 & 2.9092 & 2.9228 \\
\hline
\end{tabular}

Volume 6 Issue 1, January 2017 www.ijsr.net 


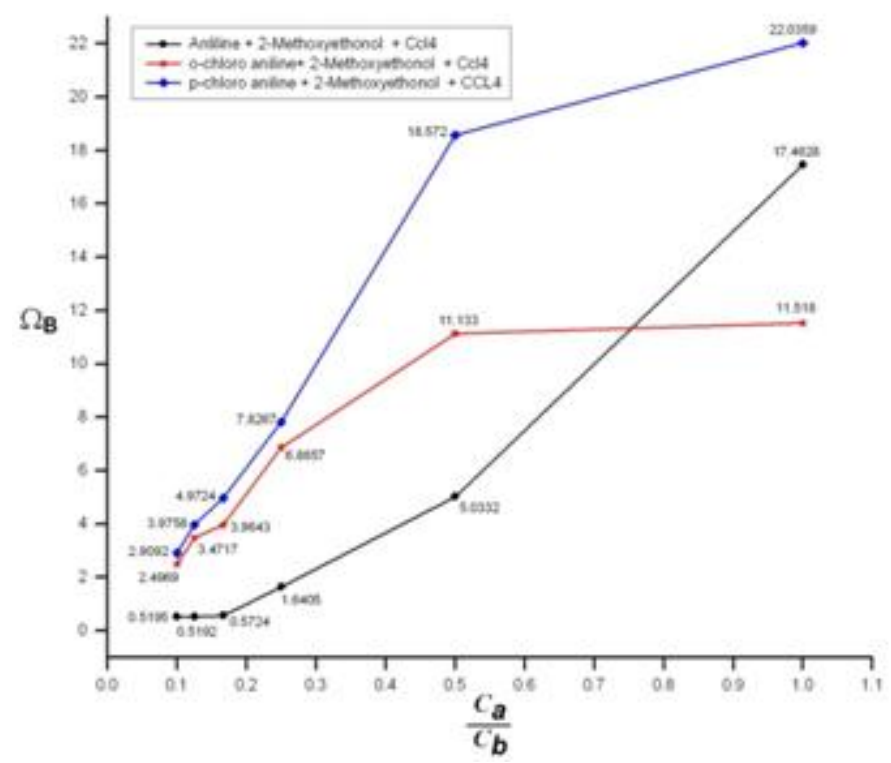

Table 2: Dipole Moments of the Components and their 1: 1 Complexes and Dipolar Increments of the Complexes2methoxyethanol+ anilines

\begin{tabular}{|c|c|c|c|c|}
\hline Systems & $\boldsymbol{\mu}_{\mathbf{a}}(\mathbf{D})$ & $\boldsymbol{\mu}_{\mathbf{b}}(\mathbf{D})$ & $\boldsymbol{\mu}_{\mathrm{ab}}(\mathbf{D})$ & $\Delta \boldsymbol{\mu}(\mathbf{D})$ \\
\hline 2-Methoxyethanol + Aniline+ $\mathrm{CCl}_{4}$ & 1.5 & 0.707 & 4.5 & 4.1 \\
\hline 2-Methoxyethanol + o-chloro aniline $+\mathrm{CCl}_{4}$ & 1.8 & 1.4 & 3.9 & 3.6 \\
\hline 2-Methoxyethanol + p-chloro aniline $+\mathrm{CCl}_{4}$ & 3.1 & 1.1 & 5.5 & 4.7 \\
\hline
\end{tabular}

\section{Results and Discussion}

The dipole moment of the donor and acceptor were determined by Huyskens method based on Onsager theory using carbon tetrachloride as solvent. These are closely agreed with the results from solution data. The values of dielectric constant, refractive indices and density measured with varying concentration of the proton donor $\mathrm{C}_{\mathrm{b}}$ are recorded in Table 1 and Table 3. The formal concentration of the proton donor $C_{a}$ is kept constant, $C_{a} \gg C_{b}$ the values of $\mu_{\mathrm{b}}$ and $\mu_{\mathrm{ab}}$ are obtained fig.1 and fig.2.The dipolar increment determined from relation (8) when a proton donor of dipole moment $\mu_{\mathrm{a}}$ forms a H-bond with a proton acceptor of dipole moment $\mu_{\mathrm{b}}$, the direction of $\mu_{\mathrm{a}}$ and $\mu_{\mathrm{b}}$ with respect to A-H ..... $\mathrm{B}$ axis can be defined as $\theta_{\mathrm{a}}$ and $\theta_{\mathrm{b}}$. If the values of $\theta_{\mathrm{a}}$ and $\theta_{\mathrm{b}}$ differs from zero.

Similar results were reported by Malathiet al. ${ }^{10}$ The plot of $\left(\mathrm{C}_{\mathrm{a}} / \mathrm{C}_{\mathrm{b}}\right)$ with $\Omega_{\mathrm{B}}$ is straight line which indicate the possibility for the formation of a 1: 1 complex (Fig 2). Hence it may be concluded that only polarization interaction is the other important contribution factor to the enhancement of dipole moment of the complexes studied here. The excess dipole moments for all the systems studied are found to be small, which is in agreement with the value reported by the excess dipole moments for all the systems studied are found to be small, which is in agreement with the values reported by Balamuralikrishnan ${ }^{11}$ for the mixtures of alcohol with aniline's. Similar results were reported by Abdel-Nour, et al [12]. The plot of $\left(C_{a} / C_{b}\right)$ with $\Omega_{B}$ is straight line which indicates the possibility for the formation of a 1:1 complex. The values are small, sometimes even negative. This explains the absence of charge transfer effects. If charge transfer effect had been there, $\Delta \mu$ would have been greater than $10 \mathrm{D}$. Since $\Delta \mu$ is less than $10 \mathrm{D}$, it may be concluded that the complexion may be only due to redistribution of electrons due to polarization effects. The dipole moments for the system on the basis of eqn. 1 it is possible to calculate the above dipole moment values. The dipole moments for the system 2-methoxyethanol in p-chloro aniline >aniline>0chloro aniline in the order of 4.7D >4.1D >3.6D > which again supports the above conclusion.It is inferred from Table 2 that the dipole moment for the halogen substituted acceptor complexes are greater than for the mono substituted acceptor complexes. On the basis of eqn. 1 it is possible to calculate the above dipole moment values.But the case is reversed in halogen substitution of donor complexes. Similar conclusions were drawn for the mixture of alcohol with substituted piper dines. Similar results were also reported by Thenappan $^{13}$ and Sabesan ${ }^{14,15}$ for alcohol mixtures. Hence it is concluded that the dipolar increment in all the systems is small due to the Polarization effect only and due to charge transfer phenomenon.

\section{Conclusion}

Dipolar increment in all the systems is small. This indicates that the polarization interactions only and it is not due to charge transfer interactions. The increase of density describes a hydrogen bond formation and specific interaction in amino group. The hydrogen bonding formation and molecular interaction in halogen substituted acceptor complexes are greater than mono substituted acceptor complexes. The dipole moments for all systems are in the order of 3.6D >4.1D >4.7D, Which again supports the above conclusion. On the basis of Eq. (1) it is possible to calculate the above dipole moment values. It is inferred from Table 2 that the dipole moment for the halogen substituted acceptor complexes are greater than for the mono substituted acceptor complexes. But the case is reversed in halogen substitution of donor complexes. 


\section{References}

[1] J.D.Hoffman,C.P.Smyth,J Am.Chem.Soc.72 171.

[2] R.H.Flwer, Proc.R.Soc.Lond.1 (1935)149.

[3] J.W.Smith, L.B. Witten, Trans.Faraday Soc.47 (1951)1307.

[4] V.Satheesh, M .Jeyaraj, J.Sobhanadri, J. Mol.Liq.64 (1995) 247.

[5] R.K.Khanna, A.Bhatnagar, J. Mol.Liq. 38 (1988) 63.

[6] P.J.Singh, K.S. sharma, Indian J.Pure Appl.Phys. 34 (1996)1.

[7] P.L. Huyskens and H.M. Vanbrabant- Govaerts, J. Mol.Struct., 84, 141 (1982).

[8] Huyskens P L, Siegel G C, Herrera F \& Cappele Ph, J MolLiq, 44 (1990) 175.

[9] OnsagarL, J. Am. Chem., 58, 1486 (136).

[10] M. Malathi, R. Sabesan and S. Krishnan, J. Mol. Liq., 109, 11 (2004).

[11] S.Balamuralikrishnan and A.U. Maheswari, J. Mol. Liq., 2, 419 (2006).

[12] K.N.A. El- Nour and S.LA. El-Messieh, J. Mol. Liq., 79, 235 (1999).

[13] M. Subramanian and T. Thennappan, Indian J. Pure Appl. Phys., 39417 (2001).

[14] T. Thenappan and M. Subramanian, Mater. Sci. Eng., 86B, 7 (2001).

[15] Sabesan R, Varadharajan R \& Sargurumoorthy M, Indian J Pure \& Appl Phys, 55B (1981) 353.

Volume 6 Issue 1, January 2017 